\title{
CIÊNCIA, TECNOLOGIA E SOCIEDADE: ABORDAGEM CRÍTICA NO ENSINO DE CIÊNCIAS
}

\section{SCIENCE, TECHNOLOGY AND SOCIETY: CRITICAL APPROACH IN SCIENCE TEACHING}

\author{
LEÃO, Marcelo Franco ${ }^{1}$ \\ GARCÊS, Bruno Pereira²
}

\begin{abstract}
RESUMO
O objetivo do estudo foi proporcionar reflexões sobre as relações entre Ciência, Tecnologia e Sociedade, bem como sobre a importância da abordagem CTS para o ensino de ciências. Trata-se de relato de experiência, ocorrida em fevereiro de 2016, durante as aulas da disciplina CTS no Curso de Especialização em Ensino de Ciências do IFMT Campus ConfresaMT. O estudo envolveu 49 pós-graduandos da Região Araguaia-Xingu. Inicialmente foi realizada a dinâmica árvore dos sonhos no intuito de apontar fragilidades e perspectivas sobre o ensino de ciências. Após, foi realizada uma tempestade de ideias sobre os termos CTS, que oportunizou conhecer suas concepções prévias. Foi proposta a leitura de artigos científicos sobre o assunto, os quais deveriam ser sintetizados em mapas conceituais. A socialização se deu por meio da galeria de ideias. Estratégias como Grupo de Verbalização e Grupo de Observação e a análise de documentários em vídeos foram utilizados para aprofundar os estudos. Logo, compreender as relações CTS e desenvolver essa abordagem ao ensinar ciências poderá contribuir para o desenvolvimento da sociedade com cidadãos críticos, autônomos e conscientes.
\end{abstract}

PalaVRas-chaVe: CTS; Ensino de Ciências; Formação de professores.

\section{ABSTRACT}

The aim of the study was to provide reflections on the relations between Science, Technology and Society, as well as on the importance of the CTS approach to science teaching. This is an experience report, held in February 2016, during the classes of the CTS course in the Specialization Course in Science Teaching of the IFMT Campus Confresa-MT. The study involved 49 post-graduate students from the Araguaia-Xingu Region. Initially the dynamic tree of dreams was realized in order to point out fragilities and perspectives on science teaching. Afterwards, a storm of ideas about the terms CTS was made, which gave opportunity to know its previous conceptions. It was proposed to read scientific articles on

\footnotetext{
${ }^{1}$ Professor do Instituto Federal de Mato Grosso (IFMT), Departamento de Ensino (Campus Confresa). e-mail: marcelo.leao@cfs.ifmt.edu.br

2 Professor do Instituto Federal do Triangulo Mineiro (IFTM), Departamento de Ensino (Campus Uberaba). e-mail: garcesquimica@gmail.com
} 
DOI: $10.12957 /$ e-mosaicos.2018.30101

the subject, which should be synthesized in conceptual maps. Socialization took place through the gallery of ideas. Strategies such as the Verbalization Group and Observation Group and the analysis of video documentaries were used to deepen the studies. Therefore, understanding CTS relationships and developing this approach when teaching science can contribute to the development of society with critical, autonomous and conscious citizens.

KeYwORDS: Methodological approach; Teacher training; Impacts.

\section{INTRODUÇÃO}

$\mathrm{Na}$ atual conjuntura, observa-se que o desenvolvimento da ciência e da tecnologia provocam transformações significativas na sociedade. Essas mudanças influenciam direta ou indiretamente na forma de vida das pessoas e consequentemente na convivência social. Para Santos (2007b), os avanços científicos e tecnológicos afetam diretamente as relações entre os indivíduos. Por isso, torna-se necessário que o ensino de ciências viabilize, por meio de suas práticas educativas, reflexões que evidenciem a importância do desenvolvimento científico e tecnológico para a sociedade.

Contudo, percebe-se que atualmente muitos professores de ciências não conseguem educar para a realidade, de forma que os conhecimentos científicos e tecnológicos possam ser aplicados em situações cotidianas. Frente a esta problemática constata-se a necessidade de adequação das práticas educativas para que seja um processo de leitura e interpretação de linguagens construídas por pessoas para explicar o mundo a sua volta, entender ciência e tecnologia de forma contextualizada.

Para Chassot (2011), são funções da educação em ciências tanto a formação pedagógica, que busca a construção de saberes e a compreensão do conhecimento científico, quanto a formação política, que defende os saberes populares e a preocupação com o bem comum social. Em outras palavras, o autor defende um ensino de ciências que promova a emancipação intelectual por meio da reflexão crítica dos avanços científicos e tecnológicos para saber agir e compreender a linguagem com que a natureza está escrita.

Segundo Santos (2007a), foram os agravantes problemas ambientais do século passado, juntamente com a intensificação das discussões sobre a natureza do conhecimento científico, que deram origem ao movimento Ciência, Tecnologia e Sociedade (CTS). Esse movimento se propagou pelo mundo inteiro, cujo intuito foi refletir criticamente sobre as relações existentes entre ciência e tecnologia, bem como o papel que desempenham na sociedade.

No Brasil, o movimento CTS ganhou espaço em meados da década de 70 (VAZ; FAGUNDES; PINHEIRO, 2009). Ainda segundo os autores, o movimento CTS se originou nos Estados Unidos e em alguns países da Europa, além do Canadá e 
Austrália, motivado pela conquista do espaço pela União Soviética. A intenção foi avaliar os impactos causados pelo progresso científico, tecnológico e sociológico.

Esse movimento pode ser entendido como uma crítica a ideia de que a Ciência é hegemônica. Ou seja, ela não pode mais ser vista como neutra, reducionista e salvacionista. A Ciência precisa ser analisada na conjuntura na qual se desenvolve, assim como a tecnologia, pois os impactos por elas provocadas são capazes de modificar a sociedade. Por tal motivo, essa abordagem tem grande relevância para a educação em ciências, pois proporciona uma formação mais ampla e crítica ao considerar as relações da ciência e da tecnologia no contexto social.

O presente estudo teve como objetivo proporcionar a estes professores, que estão em formação Lato-Sensu em Ensino de Ciências, reflexões sobre as relações existentes entre Ciência, Tecnologia e Sociedade (CTS), bem como sobre a importância dessa abordagem metodológica para o ensino de ciências na atualidade. Esses conhecimentos são imprescindíveis para que a educação exerça seu papel de agente capaz de transformar a sociedade.

\section{Discursos Teóricos sobre a AbORdagem CTS}

Na contemporaneidade, é quase impossível pensar em convivência social sem relacionar com a tecnologia que a permeia, tampouco é inviável discutir sobre as tecnologias atuais sem recorrer a ciência envolvida, ou seja, esses são elementos intimamente relacionados e que se complementam. Assim, faz-se necessário promover reflexões sobre as relações entre a ciência, a tecnologia e a sociedade, bem como sobre suas implicações para o ensino de Ciências (GARCÊS; LEÃO, 2017).

Essa tendência é confirmada por Mamede e Zimmermann (2005) que consideram cada vez mais intensa a presença da ciência e da tecnologia na sociedade contemporânea. Segundo as autoras, se os avanços científicos e tecnológicos têm repercussões diretas sobre a forma de vida das pessoas, o ensino de ciências, constitui-se então em uma importante estratégia de inclusão das pessoas, dos estudantes, na vida em sociedade, como protagonistas e não apenas como meros espectadores.

Outro aspecto a ser considerado, segundo Garcês e Leão (2017), é a maneira com que ocorre o processo da divulgação e popularização dos conhecimentos científicos e tecnológicos, na educação escolar e na educação não formal. Esse processo é determinante na forma da sociedade conceber ciência e tecnologia, bem como valer-se desses conhecimentos em suas situações cotidianas, ou seja, tamanha é a necessidade de discutir as relações CTS em sala de aula.

O termo Ciência tem origem no latim (Scientia), que significa conhecimento. Ela pode ser compreendida como o conhecimento fundamentado e, por isto, necessário para a convivência social. Atualmente, a Ciência não pode ter a pretensão de ser absoluta, da verdade incontestável, do cientificismo criticado por Auler (2003), 
mas sim algo passível de comprovação, verificação e aceitação por uma comunidade. Este estudo se constrói de forma argumentativa sustentado em bases conceituais sólidas para que não sejam meras suposições que configuram o senso comum.

Segundo Teixeira (2003), a ciência ensinada pelos professores na escola permanecem para os estudantes por um período pouco além da etapa escolar. Isso mostra que não ocorre, na maioria das vezes, a alfabetização científica a que se propõe a abordagem CTS. Assim, são observados e discutidos de maneira superficial no ensino de ciências uma grande quantidade de vocabulários sem que ocorra a devida correspondência conceitual, ou seja, é realizado o estudo de alguns objetos e fenômenos sem o comprometimento com a compreensão de que se trata.

Frente a essa problemática que Mamede e Zimmermann (2005) ressaltam sobre a importância de compreender a ciência como prática social, pois além de inserir o contexto da produção desses conhecimentos, também são discutidas as condições dessa produção, bem como a divulgação e aplicação do conhecimento científico. Dessa forma, a ciência é apresentada e concebida como bem que a sociedade controla e detém.

A tecnologia, por sua vez, pode ser compreendida como o conjunto de conhecimentos diretamente aplicáveis que permite controlar e modificar sistemas e assim interferir no mundo. Nesse sentido, é preciso considerar que tecnologia e ciência são termos indissociáveis, ou seja, a tecnologia está diretamente associada ao conhecimento científico. Contudo, essa proximidade leva a uma interpretação equivocada que reduz a tecnologia como se fosse a ciência colocada em prática, uma espécie de ciência aplicada (VAZ; FAGUNDES; PINHEIRO, 2009).

Segundo o dicionário de filosofia, o termo tecnologia corresponde ao estudo dos processos técnicos de determinado setor da produção industrial ou de vários setores. Já sociedade é o termo designado para o grupo de indivíduos entre os quais ocorrem relações humanas de comunicação (ABBAGNANO, 2007).

Em seus estudos, Vaz, Fagundes e Pinheiro (2007), definem sociedade como sendo um corpo orgânico e estruturado em todos os níveis da vida social, ou seja é a organização que reúne os indivíduos de uma mesma região geográfica, estando todos sujeitos a iguais condições de sistemas econômico, político e cultural.

As pessoas de uma sociedade estão sujeitas as mesmas leis, aos mesmos direitos e deveres, ao mesmo regime político e as mesmas regras e costumes da cultura que a convivência desse grupo estabeleceu. Além de ser formada por esse grupo de pessoas que vivem em um mesmo sistema, os autores supracitados acreditam que essa organização está sujeita às mudanças provocadas pelos avanços e conhecimentos da ciência e da tecnologia.

Na verdade, a educação sempre está a serviço de um determinado tipo de cidadania. Pode atuar de modo crítico, reflexivo, fomentando a emancipação popular, ou pelo contrário, pode ser responsável pela 
formação de indivíduos acríticos, obedientes e conformistas, contribuindo para manutenção de um quadro de imobilismo coletivo diante das questões sociais (TEIXEIRA, 2003, p. 89).

Contudo, Santos (2007a) alerta que a maioria dos professores de ciência apresentam resistência e até dificuldades em promover reflexões e debates que contemplem questões sociais. Para o autor, essa dificuldade faz com que, muitas vezes, a abordagem de temas CTS estejam restritos a meras ilustrações de aplicações tecnológicas sem a relação devida com as implicações sociais.

Para o autor supracitado, é preciso inserir a abordagem CTS no ensino de ciências de maneira a favorecer a criticidade. Em outras palavras, é necessário que ocorra um amplo debate em sala de aula sobre as questões sociais, culturais, econômicas, políticas, culturais, éticas e ambientais para que as pessoas compreendam o papel da ciência e da tecnologia na sociedade. Ao mesmo tempo, o autor alerta ser fundamental a compreensão conceitual dos temas CTS, pois a tomada de decisão não se baseia apenas em valores e atitudes, mas também em compreender os conceitos científicos envolvidos.

\section{Procedimentos Metodológicos}

Esse estudo caracteriza-se como relato de experiência cuja abordagem é qualitativa. Para Martins (2012), um estudo de abordagem qualitativa considera relevante a realidade subjetiva dos indivíduos participantes, que neste caso em específico são os professores de ciências em formação. Já sobre o relato de experiência, Medeiros (1997) define como um estudo descritivo que evidencia os resultados de uma investigação sem ter um rigor metodológico extremamente formal para apresentar seus resultados. Esse caráter mais informal possibilita flexibilizar a linguagem empregada, bem como a estruturação do texto, de maneira a tornar a leitura mais próxima e com significado para os interlocutores.

Essa experiência pedagógica ocorreu no mês de fevereiro do ano de 2016, durante as aulas da disciplina de Ciência, Tecnologia e Sociedade, componente curricular do curso de Pós-Graduação Lato-Sensu em Ensino de Ciências do Instituto Federal de Educação, Ciência e Tecnologia de Mato Grosso (IFMT), Campus Confresa. Participaram do estudo 49 pós-graduandos do curso, dentre eles professores de Biologia, Física, Química e Pedagogia da Região Araguaia-Xingu. Os encontros ocorreram em cinco turnos aos finais de semana totalizando 20 horas essa formação.

A ementa da disciplina contempla aspectos importantes, tais como: Estudo das relações entre ciência, tecnologia, sociedade (CTS) e suas implicações para o ensino de Ciências. Aspectos da divulgação e popularização dos conhecimentos científicos e tecnológicos, na educação escolar e na educação não formal. Estudos 
sobre a relação entre CTS em suas diversas dimensões, tais como: histórica, filosófica, ética, política, econômica, cultural e artística. Aspectos curriculares, do ensino e da aprendizagem em Ciências na perspectiva de ciência, tecnologia e sociedade. Estudos de gêneros textuais e textos científicos. Relações entre escola e circulação pública de conhecimentos científicos. Temas de ciência, tecnologia e sociedade e as questões contemporâneas; políticas adotadas em Ciência e Tecnologia e suas repercussões, com ênfase nos países em desenvolvimento e a educação. Significados, concepções ou expectativas de alunos e professores sobre CTS.

Essa disciplina compõe o primeiro módulo do curso, intitulado "Fundamentação do Ensino de Ciências". A metodologia adotada, as atividades propostas e os recursos utilizados durante essas aulas visaram proporcionar instrumentos para que os pós-graduandos compreendessem a relação entre CTS em suas diversas dimensões, os aspectos curriculares nessa perspectiva e da divulgação e popularização dos conhecimentos científicos e tecnológicos, na educação escolar e na educação não formal.

Após a apresentação da disciplina (Ementa, Referências, Planejamento da aula e Atividade extraclasse), foi proposta a dinâmica "Árvore dos sonhos", que teve origem na segunda Conferência Mundial para o Meio Ambiente e Desenvolvimento (ECO-92) e foi adaptada de uma das etapas previstas pela oficina do futuro ${ }^{3}$ (BRASIL, 2012). A atividade foi dividida em três etapas, inicialmente, os pósgraduandos fizeram uma crítica ao ensino de ciências que identificam como pedras no caminho, seja como estudantes, seja como profissional ministrando as aulas. Em seguida, foi o momento de refletir sobre os sonhos para um Ensino de Ciências de qualidade, representados pelas folhas da árvore. Para finalizar, foram formados grupos que planejaram estratégias para alcançar os sonhos, que foram escritas no tronco da árvore.

Na sequência foram apresentados e discutidos os vídeos "O que seria de nós sem a Ciência e a Tecnologia" e "O papel do professor - Rubem Alves". Após, foi proposta uma tempestade de ideias para levantar os conceitos prévios que tinham sobre Ciência, Tecnologia e Sociedade. Houve então uma discussão sobre os conteúdos programáticos.

A turma foi dividida em grupos menores para ser possível a realização de atividades de estudos dirigidos (leituras de artigos científicos sobre a temática). Desse estudo foi proposta a elaboração de mapas conceituais como maneira de sintetizar os artigos lidos. Segundo Moreira (2006), os mapas conceituais podem ser considerados como esquemas gráficos para estruturar os conceitos estudados, ou seja, são esquemas para representar a estrutura básica de um conhecimento ou parte dele.

\footnotetext{
${ }^{3}$ Técnica que ajuda a conduzir os passos de preparação da Agenda 21 na Escola e de qualquer outro projeto coletivo.
} 
A apresentação dos mapas elaborados pelos grupos ocorreu na forma de galeria de ideias (gallery walk), uma variação do método Jigsaw, idealizado com o objetivo de reduzir a discriminação e promover diversidade em sala de aula (ARONSON \& BRIDGEMAN, 1979). Todos eles foram distribuídos e fixados nas paredes de maneira a formar uma espécie de galeria de arte. Um integrante de cada grupo que construiu os mapas constituiu um novo grupo que, ao visitar a galeria, tinha a oportunidade de explicar o mapa construído aos integrantes de seu novo grupo que construíram os demais, e assim sucessivamente.

Em outro momento, foi proposta a estratégia de ensino Grupo de Verbalização e Grupo de Observação (GV/GO) para exercitar a reflexão e a contradição do polêmico assunto "agrotóxicos". Os dois textos previamente selecionados para a atividade foram: A verdade sobre os agrotóxicos (Revista Veja de 14/01/2012) e A mentira sobre os agrotóxicos (Blog A medicina dos alimentos de 13/05/2012).

A análise da circulação pública dos conhecimentos científicos ocorreu por meio da observação de diferentes notícias divulgadas por diferentes veículos sobre a fosfoetanolamina sintética e os estudos sobre a cura do câncer.

Em seguida foi apresentado e discutido o filme/documentário "Ilha das flores", de Jorge Furtado (1989). Antes de finalizar o estudo presencial, foi encaminhada a atividade extraclasse, que compreendeu a elaboração de uma sequência didática para discutir um tema e/ou questão contemporânea com estudantes da Educação Básica. Por meio da atividade extraclasse foi possível elaborar o presente material.

No encerramento das atividades, foi solicitado que os participantes realizassem uma avaliação da aula por escrito. Foram distribuídas folhas sulfites partidas ao meio e dito que ficassem livres para se identificar ou não. Não foi formulada uma questão em específico, mas solicitado que apontassem, de maneira subjetiva, os aspectos positivos e negativos desse momento formativo, além do que julgaram mais significativo.

Para garantir o anonimato dos sujeitos da pesquisa, os nomes foram substituídos por siglas da seguinte maneira: P1 (pós-graduando 1), P2 (pósgraduando 2) e assim sucessivamente. As discussões dos resultados foram realizadas sob a luz do referencial teórico utilizado.

\section{Resultados e Discussões}

A dinâmica árvore dos sonhos possibilitou realizar uma crítica ao ensino de ciências. Inicialmente os pós-graduandos foram convidados a lançar as pedras existentes no caminho, seja na formação recebida em suas trajetórias estudantis, seja enquanto professores. Todas as etapas dessa dinâmica serão descritas a seguir, bem como os elementos contidos na ilustração (Fig. 1). 
Algumas das pedras reveladas foram trazidas para esse texto: o ensino é baseado na memorização; a maioria das aulas são teóricas e descontextualizadas; distantes da realidade, o que dificulta a interpretação e compreensão; falta de profissionais formados nas áreas de ciências da natureza e falta de laboratório de ciências nas escolas; falta de didática dos professores nas aulas; alienação: inibição no pensar (não ter tempo suficiente para ser capaz de pensar por si próprio); exploração somente do livro didático; falta um olhar mais humanizado dentro da escola, às vezes falta respeito a cultura do estudante; ensino tradicional, onde só há uma resposta exata, ou seja o conhecimento é pronto e acabado; ensina-se muito a reprodução ao invés da produção de conhecimento; avaliação muito incompatível com a realidade; os professores sem didática ou sem paciência ou não se preocuparam com a qualidade do ensino.

Figura 1 - Etapas da construção da árvore dos sonhos pelos pós-graduandos

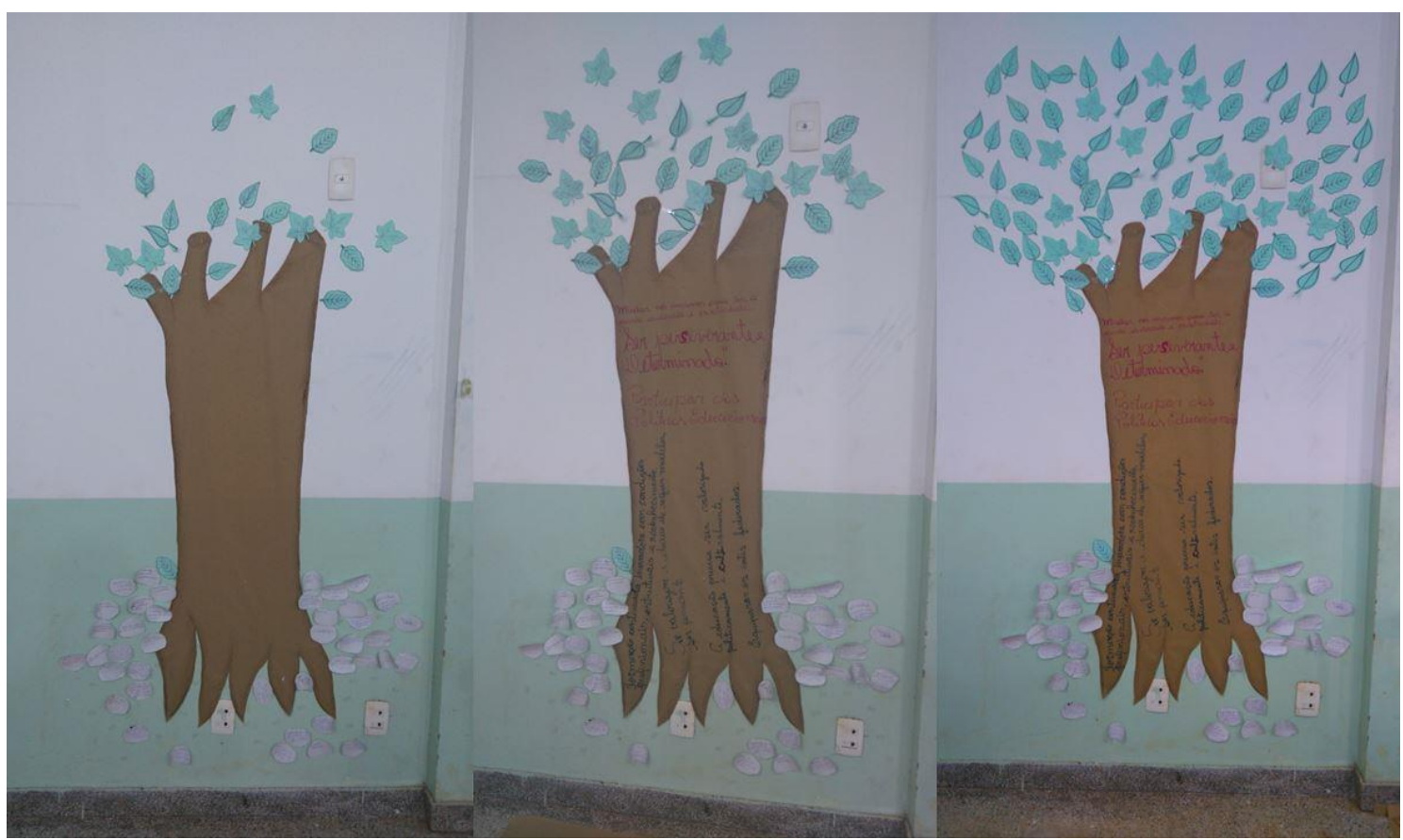

Fonte: Arquivo pessoal (2016)

Percebe-se que o ensino de ciências continua precisando ser repensado para que de fato venha a contribuir com a vida das pessoas. Conforme os posicionamentos apresentados, verifica-se que a concepção predominante ainda é a de ciência como dogma, a qual não admite o erro, a dúvida ou o questionamento, a ciência estante e isolada, desarticulada da realidade e que acaba por perder a serventia. Por isso, mais do que nunca, é preciso desenvolver essa reflexão crítica defendida por Chassot (2011), Auler (2003) e Santos (2007b). 
DOI: $10.12957 /$ e-mosaicos.2018.30101

As folhas que, intencionalmente ficavam na parte superior da árvore, representavam os sonhos, ou seja, as metas a serem alcançadas pelo ensino de ciências. Alguns desses sonhos foram: ver a sociedade mais humanizada; ter educação de qualidade para todo; respeitos as diferenças individuais e valorização profissional; ter mais investimentos em formação dos profissionais para o ensino; ensino que proporcione a criatividade, que leve a sabedoria e ao entendimento; educação transformadora; laboratórios para educação básica para favorecer a compreensão; escolas bem estruturadas e equipadas: biblioteca, laboratórios, lazer, além de professores capacitados; educar pela pesquisa, melhorar o relacionamento escola e sociedade; um ensino com igualdade para todos e com profissionais capacitados; que a escola seja mais atrativa e divertida; ajudar na formação de cidadãos críticos, que não se amoldem ao que a mídia e a sociedade ditam além de serem sensíveis ao próximo.

Os sonhos desses professores giram entorno de que o ensino de ciências possa fazer a diferença na vida das pessoas, que seja algo útil, contextualizado e real. Essas mudanças são possíveis quando o ensino de ciências proporciona aos estudantes analisarem criticamente os impactos causados pelo progresso cientifico, tecnológico e sociológico como é defendido no Brasil desde 1970 (VAZ; FAGUNDES; PINHEIRO, 2009).

As estratégias foram colocadas no tronco da árvore, a fim de nutrir os sonhos, independentemente das pedras que podem prejudicar o ensino de ciências. As estratégias propostas foram: formação continuada inovadora com condições profissionais, estruturais e reconhecimento; se valorizar e deixar de seguir modelos, ser pensante; a educação precisa ser valorizada politicamente e culturalmente; equiparar os entes federados; mudar nós mesmos para ter a devida dedicação e criatividade; ser perseverante e determinado; participar das políticas educacionais.

Ações individuais e coletivas foram as estratégias propostas pelos pósgraduandos, destacando que os caminhos para um melhor ensino de ciências está em aspectos intra e interpessoais dos professores. As políticas educacionais também surgem como essenciais para promover as mudanças necessárias para alcançar os sonhos.

A dinâmica atingiu seu objetivo de desenvolver a análise crítica das pessoas envolvidas sobre o ensino de ciências, além de constituir-se como um momento privilegiado para se debater sonhos, problemas e ações conjuntas, assim como indica a oficina do futuro (BRASIL, 2012).

As palavras listadas durante a atividade tempestade de ideias, nos remetem ao entendimento prévio que os professores em formação tem sobre Ciência: produção, conhecimento, construção, investigação, criação, descoberta, experiência, vida, pesquisa, discussão, solução, reflexão, erro, evolução, natureza, curiosidade, pensamento, crítico, estudo e fenômeno. 
Já por Tecnologia, os pós-graduandos mencionaram: necessidade, inovação, rapidez, poder, redes, produção, reflexão, evolução, automação, alienação, celular, robô, máquinas, conexão, agilidade, dependência e comunicação. Associadas ao termo sociedade citaram as seguintes palavras: cidadania, política, cultura, humanização, respeito, direitos, cuidados, pessoas, grupos, tribos, organização, regras e deveres.

Percebe-se que os termos são bastante próximos e amplos, por isso a interpretação de tais termos irá depender dos contextos históricos nos quais são propostos. $\mathrm{O}$ intuito de levantar essas concepções sobre os termos de maneira isolada foi justamente para que os pós-graduandos pudessem perceber que mesmo nessas condições individuais os termos estão intimamente relacionados. Outro aspecto observado é que as definições, mesmo que expressas com outras palavras, aproximam-se daquelas contidas no dicionário de filosofia (ABBAGNANO, 2007).

Os mapas conceituais produzidos mostram que os pós-graduandos compreendem a estrutura básica e a função dos mapas conceituais. Durante a galeria de ideias para a apresentação destes, foi possível observar que o método contribuiu para a troca de informações, conceitos e sentimentos sobre alfabetização científica e letramento científico, pois promoveu grande interação entre os participantes. Foi possível estabelecer um ambiente de aprendizagem adequado para a construção colaborativa de conceitos a partir das experiências e leituras dos pósgraduandos.

Cabe aqui apontar que durante a aula os mapas foram construídos no formato de cartazes em papel pardo com o auxílio de pincéis atômicos coloridos. Para esse estudo, um dos mapas foi transcrito na íntegra por meio do software CmapTools $($ C (Fig. 2). Foram grandes as trocas que ocorreram durante o momento em que ocorreu a socialização do estudo dirigido (Fig. 3).

Figura 2 - Mapa conceitual sobre CTS construído com a síntese dos artigos

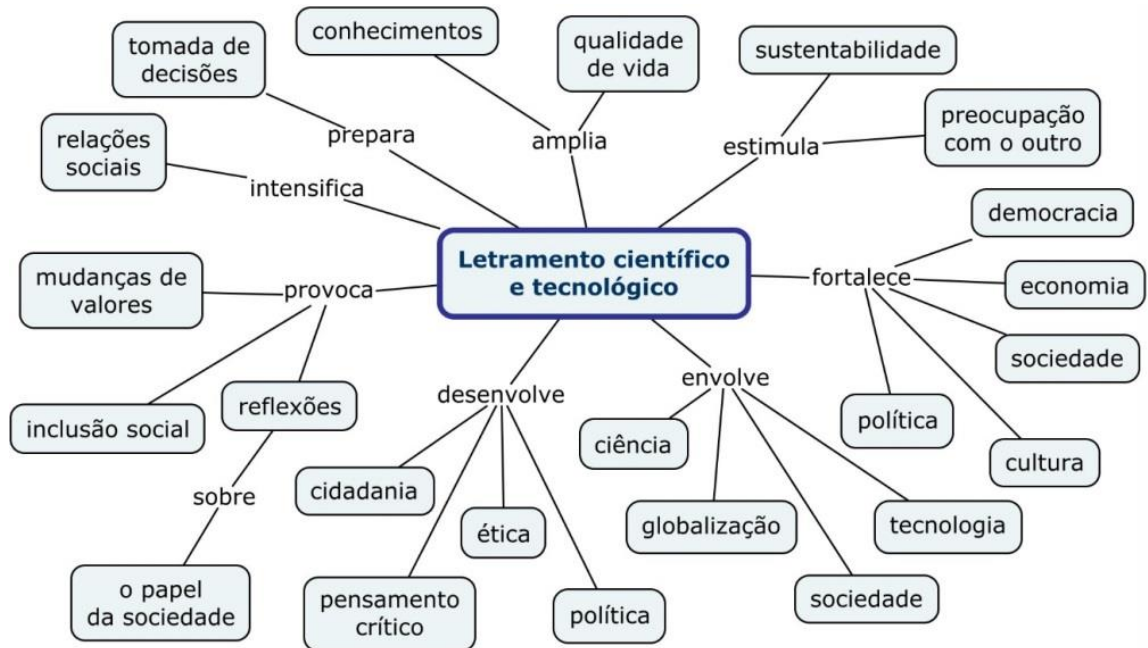

Fonte: Elaborado pelos pós-graduandos e transcrito para o CmapTools (2016). 
Figura 3 - Galeria de ideias para socializar as sínteses dos textos estudados

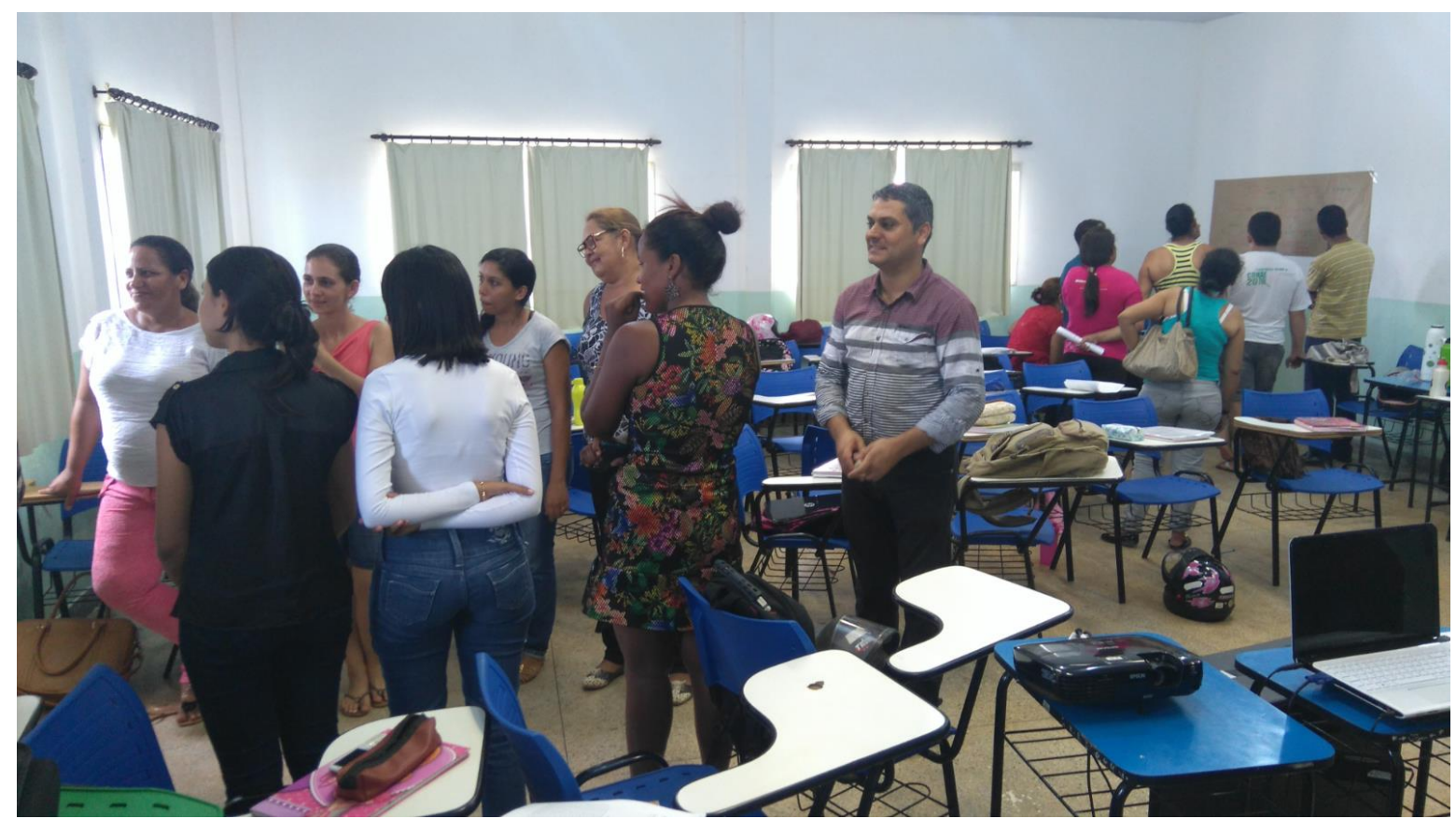

Fonte: Arquivo pessoal (2016).

Foram propostas atividades para os Ensinos Fundamental e Médio, utilizando temas presentes no cotidiano dos estudantes, além de atuais, como o uso de anabolizantes, suplementos alimentares, cultura midiática, transgênicos, agrotóxicos, dependência química, automedicação, fitoterápicos, lixo, queimadas, dentre outros (GARCÊS; LEÃO, 2017).

$\mathrm{Na}$ atividade GV/GO, os pós-graduandos foram divididos em dois grupos, um que verbalizou suas leituras e posicionamentos sobre os agrotóxicos e outro grupo que observou atentamente e analisou as informações apresentadas. Após o período de verbalização, o grupo de observação fez apontamentos importantes sobre a temática, sendo que essa atividade proporcionou realizar uma reflexão crítica da realidade.

A realização dessa atividade foi simular a situação de aprendizagem proposta por Mamede e Zimmermann (2005), que propuseram reflexões sobre o letramento científico e sobre a abordagem CTS na formação inicial de professores. Em ambos os casos, foi possível aos participantes estabelecer relações entre os conceitos da ciência com questões sociais, ou seja, a formação proporcionada visou relacionar os conhecimentos científicos com a vida cotidiana.

A partir da atividade extraclasse (elaboração de uma sequência didática) resultou a produção de um e-book intitulado "Ciência, Tecnologia e Sociedade: 
Propostas para a sala de aula". Segundo Garcês e Leão (2017), todas as sequências didáticas elaboradas têm 0 intuito de proporcionar um material para ser disponibilizado gratuitamente aos professores, para que suas práticas educativas possam apresentar a Ciência e a Tecnologia a favor da sociedade.

Algumas atividades foram propostas para a Educação no Campo e Educação de Jovens e adultos, trazendo a realidade regional para dentro da sala de aula e destacando a importância do contexto na atuação do professor. Todas as sequências elaboradas percorreram os caminhos da alfabetização científica e da didática das ciências a fim de facilitar o acesso à propostas de ensino contextualizadas, interdisciplinares e, utilizando a abordagem CTS.

A avaliação da disciplina, realizada no término da aula, revelou que os participantes consideraram bastante produtivo e proveitoso o estudo realizado sobre a abordagem CTS. Alguns posicionamentos nesse sentido são: "Os texto foram bem trabalhados e as dinâmicas deixaram a aula muito agradável" (P1). "Avalio essas aulas como diferenciadas e muito proveitosas, com destaque para os trabalhos em grupos que oportunizaram aprofundar as discussões sobre a importância da CTS" (P3).

"A aula foi muito boa, aprendi muito e certamente levarei para a minha prática em sala de aula" (E6). "Considero que foi muito proveitosa, não só para os que já são professores, mas também para os futuros, pois nos faz entender que é possível melhorar a educação e que o ensino de ciências precisa ser contextualizado" (E10). "Quero aqui ressaltar a coragem de mudar, de fazer diferente. Confesso que deu vontade de voltar a lecionar química dessa maneira dinâmica. Foi muito bom mesmo!" (E11).

"Avalio o quanto o estudo desta disciplina foi proveitoso, todas as atividades bem planejadas e dinâmicas que nos levaram a realizar essa reflexão crítica sobre qual ciência estamos ensinando" (E17). "Considero que a aula foi envolvente e atrativa, que a ciência de fato não é dogmática e sim dinâmica e em constante transformação e com novas metodologias que valorizem o protagonismo do aluno vai ser fácil estudar ciências" (E26). "Com essa aula entendi que os estudantes buscam o novo, algo que os provoque e que mude alguns hábitos. $O$ ensino de ciências nessa abordagem dá significado e, se conseguirmos ensinar assim, creio que seremos professores bem melhores" (E33). "A metodologia utilizada foi muito agradável e ajudou muito nas discussões teóricas. Das discussões que tivemos, certamente todos levarão conhecimentos para a vida profissional" (E41).

Todas as atividades aqui relatadas foram desenvolvidas no intuito de promover o aprofundamento sobre essa importante temática nessa formação continuada de professores, o que foi confirmado pela avaliação dos participantes. Esse propósito vem ao encontro do que pensa Teixeira (2003) ao afirmar que é preciso aprofundar, cada vez mais, as reflexões sobre a Concepção CTS para o ensino de ciências. 


\section{CONSIDERAÇões FinAIS}

Abordagens CTS descritas anteriormente exploram os conhecimentos de forma mais ampla, o que permite o estabelecimento de correlações, sempre acompanhada de reflexões críticas.

É importante que, ao trabalhar a abordagens CTS em sala de aula, o professor estabeleça um ambiente dialógico, encorajando a participação ativa dos estudantes para que a socialização dos saberes seja ponto de partida para a construção do conhecimento, promovendo a alfabetização e o letramento científico.

Logo, é preciso que o ensino de ciências seja capaz de discutir sobre as questões sociais, ou seja, sobre os elementos presentes no cotidiano das pessoas. Nesse contexto, a abordagem CTS é uma aliada dos professores de ciências, pois proporciona reflexão crítica que leva a compreensão de que a ciência e a tecnologia precisam estar a serviço da sociedade e não o contrário.

Para concluir, acredita-se que as reflexões de aspectos sociocientíficos podem favorecer o desenvolvimento de uma educação crítica e emancipatória, em que os cidadãos são capazes de questionar e intervir frente ao modelo de desenvolvimento científico e tecnológico.

\section{REFERÊNCIAS}

ABBAGNANO, N. Dicionário de Filosofia./ Nicola Abbagnano; tradução da 1. ed. Brasileira coordenada e revista por Alfredo Bossi; revisão da tradução e tradução de novos textos por Ivone Castilho Benedetti, 5. ed. São. Paulo: Martins Fontes, 2007.

ARONSON, E.; BRIDGEMAN, D. Jigsaw Groups and the Desegregated Classroom: In Pursuit of Common Goals. Personality and Social Psychology Bulletin, v. 5, n. 4, 1979.

AULER, D. Alfabetização científico-tecnológica: um novo "paradigma"? ENSAIO Pesquisa em Educação em Ciências, v. 5, n.1, 2003.

BRASIL. Ministério da Educação. Secretaria de Educação Continuada, Alfabetização, Diversidade e Inclusão. Formando Com-vida, Comissão de Meio Ambiente e Qualidade de Vida na Escola: construindo Agenda 21 na escola / Ministério da Educação, Ministério do Meio Ambiente. - 3. ed., rev. e ampl. - Brasília : MEC, Coordenação-Geral de Educação Ambiental, 2012.

CHASSOT, A. Alfabetização científica: questões e desafios para a educação. Ijuí: UNIJUÍ, 2011. 
GARCES, B. P.; LEÃO, M. F . Ciência, Tecnologia e Sociedade: Propostas para a Sala de Aula. 1. ed. Uberlândia-MG: Edibrás, 2017.

MAMEDE, M. A.; ZIMMERMANN, E. Letramento Científico e CTS na Formação de Professores para o Ensino de Ciências. Enseñanza de las Ciencias, Barcelona, v. extra, n.o1, p. 03-21, 2005.

MARTINS, R. P. Informação e conhecimento: uma abordagem dos sistemas de recuperação de informações a partir das interações sociais. Perspectivas em Ciência da Informação, Belo Horizonte, v. 13, n. 2, p. 77-87, maio/ago. 2008.

MEDEIROS, J. B. Redação Científica: a prática de fichamentos, resumos e resenhas. 3. ed.. São Paulo: Atlas, 1997.

MOREIRA, M. A. Mapas conceituais e diagramas V. 1. ed. Porto Alegre: Edição do Autor, 2006.

SANTOS, W. L. P.. Contextualização no ensino de ciências por meio de temas CTS em uma perspectiva crítica. Ciência \& Ensino (UNICAMP. Impresso), v. 1, p. 1-12, $2007 a$.

SANTOS, W. L. P. dos. Educação científica na perspectiva de letramento como prática social: funções, princípios e desafios. Revista Brasileira de Educação v. 12 n. 36 set./dez. $2007 b$.

TEIXEIRA, P. M. M. Educação Científica e Movimento C.T.S. no quadro das tendências pedagógicas no Brasil. Revista Brasileira de Pesquisa em Educação em Ciências, ABRAPEC: Porto Alegre, v. 3 (1), n.1, p. 88-102, 2003.

VAZ, C. R.; FAGUNDES, A. B.; PINHEIRO, N. A. M. O Surgimento da Ciência, Tecnologia e Sociedade (CTS) na Educação: Uma Revisão. In: Simpósio Nacional de Ensino de Ciência e Tecnologia, 2009, Ponta Grossa. I SINECT, 2009.

Recebido em 24 de agosto de 2017 Aceito em 08 de abril de 2018 